\title{
Advances
}

in

\section{Applied Probability}

Editor-in-Chief: J. GANI

Editors: E. SPARRE ANDERSEN, D. BLACKWELL, B. GNEDENKO, J. HÁJEK, E. J. HANNAN, D. G. KENDALL, J. F. C. KINGMAN, K. KRICKEBERG, P. A. P. MORAN, J. NEVEU, K. R. PARTHASARATHY, R. PYKE, C. A. B. SMITH, L. TAKÁCS

Volume 1

Number 2

A u t u m 1969

Published by the

APPLIED PROBABILITY TRUST 


\section{Advances in Applied Probability}

This is a companion publication to the Journal of Applied Probability published by the Applied Probability Trust. It contains review and expository papers in Applied Probability, as well as mathematical and scientific papers of interest to probabilists. An annual volume of approximately 250-300 pages will be published in two numbers appearing in the Spring and Autumn.

\section{Submission of papers}

Submissions to the Advances may be of three kinds:

(1) review and expository papers of about 40-50 printed pages in length, surveying a field of Applied Probability; these will be paid for on acceptance at the rate of $£$ stg. 100 ( $\$ 240)$;

(2) long research papers in Applied Probability, which may include expository material;

(3) shorter expository papers on branches of mathematics of interest to probabilists; papers outlining areas in the biological, physical, social and technological sciences in which probability models can be usefully developed; papers in Applied Probability presented at conferences which do not publish their proceedings.

These should be sent to any one of

\section{Editor-in-Chief:}

J. GANI Department of Probability and Statistics, The University, Sheffield, S3 7RH, England

\section{Editors:}

E. SPARRE ANDERSEN Københavns Universitets Matematiske Institut, ${ }^{H}$. C. Orsted Institutet, Universitetsparken 5, København Ø, Denmark.

D. BLACKWELL Department of Statistics, University of California, Berkeley, California 94720 , U.S.A.

B. GNEDENKO Sector I, Flat 75, Moscow University, Moscow B-234, U.S.S.R.

J. HÁJEK Department of Statistics, Charles University. Sokolovska ul. 83, Prague 8, Czechoslovakia.

E. J. HANNAN Department of Statistics, Australian National University, P.O.Box 4, Canberra, Australia 2600.

D. G. KENDALL Statistical Laboratory, Cambridge University, Cambridge, England.

J. F. C. KINGMAN Mathematical Institute, 24-29 St. Giles, Oxford OXI 3LB, England.

K. KRICKEBERG Institut für angewandte Mathematik, Universität Heidelberg, Berliner Strasse 17, 6900 Heidelberg 1, W. Germany.

P. A. P. MORAN Department of Statistics, Australian National University. P.O.Box 4, Canberra, Australia 2600.

J. NEVEU Département de Mathématiques, Facultés des Sciences, Université de Paris, 11 Rue Pierre-Curie, Paris 5, France.

K. R. PARTHASARATHY Statistical Laboratory, Department of Mathematics, The University, Manchester, M13 9PL, England.

R. PYKE Department of Mathematics, University of Washington, Seattle, Washington 98105 , U.S.A.

C. A. B. SMITH Galton Laboratory, University College, Wolfson House, 4 Stephenson Way, London N.W. 1, England.

L. TAKÁCS Department of Mathematics, Case Western Reserve University, University Circle, Cleveland, Ohio 44106, U.S.A. 